\title{
Evaluation and Utilization of Soybean Germplasm for Resistance to Cyst Nematode in China
}

\author{
Ying-Hui Li, Xiao-Tian Qi, Ruzhen Chang and Li-Juan Qiu \\ The National Key Facility for Crop Gene Resources and Genetic Improvement (NFCRI) / \\ Key Lab of Germplasm Utilization (MOA), Institute of Crop Science, \\ Chinese Academy of Agricultural Sciences, 100081 Beijing, \\ P. R. China
}

\section{Introduction}

The total area of Soybean Cyst Nematode ( $\mathrm{SCN}$, Heterodera glycines Ichinohe)-infected soybean (Glycine max (L.) Merr.) in China increases each year, resulting in substantial yield losses. It becomes more and more important to discovery and incorporate new gene into breeding program for developing resistant cultivars. In this paper, we introduced more than 400 resistant accessions which were resistant to race 1, 2, 3, 4 and 5, especially some ones with resistance to multiple races. These resistant accessions were used to construct SCN applied core collection that consisted of 29 accessions but could represent more than $70 \%$ of genetic diversity of the whole resistant collection. By using linkage and association mapping methods, 15 QTLs, 22 SSR markers, 5 SNP markers and 1 SNP haplotype were identified associated with resistance to SCN. Moreover, one resistant candidate gene GmHs1pro-1 was cloned and analyzed for sequence variation. In addition, 11 SNP markers were developed from candidate genes rhg1 and Rhg4 respectively, which had been used to analysis genetic diversity and genetic relationship among soybean accessions. However, it is essential to discover novel gene from the resistant accession and explore new breeding methods for accelerating SCN resistant soybean improvement.

\section{Background information}

SCN was one of the most destructive pests for soybean production and easily cause significant agricultural problem. Annual economic losses associated with SCN have been estimated to be as high as \$120 million in China. It was firstly found in northeast China in 1899 and then in Korean, Japan, U.S.A, Columbia, Canada, Brazil, Argentina, Russia, and Indonesia and the other counties. Now it has infested the main soybean cultivation regions of China. The life cycle of SCN is divided into three stages: egg, larva, and dult. Larva, the major infection form, infects and damages soybean plants via mechanical injury, physiological damage and induction of infection by another pathogens. In 1952, Ichinohe defined SCN as a separate species, Heterodera glycines Ichinohe based on the detailed morphological study. Within the species, SCN is extremely variable genetically. Ross (1962) firstly noticed that the isolates of $H$. glycines from different places in U.S.A were different when they inoculated to the soybean 
Plant Introduction (PI) 88788, suggesting that the genetic diversity was existed among populations of the nematode. For developing a classification scheme that would separate the major genetic groups for host compatibility within $H$. glycines, a race test was proposed (Golden et al., 1970). Using four resistant (Peking, Pickett, PI90763 and PI88788) and one susceptible accessions (Lee) as differential host, a four-race scheme was established based on comparative development of females (Golden et al., 1970). Later, for meeting with the demands of adequately description the extensive genetic diversity of $H$. glycines populations that existed in soybean production areas, a 16-race identification system was developed taken the four-race system as the base (Riggs \& Schmitt, 1988). Until now, 14 races had been discovered except for race 11 and 13 worldwide. For avoiding the implication of genetic uniformity or predictability and efficiently document and discuss population differences, HG Type scheme was also developed (Niblack et al., 2002) using seven differential hosts including PI58402 (Peking), PI88788, PI90763, PI437654, PI209332, PI89772 and PI548316). Since most of resistance accessions were identified using race designations and 16-race identification system was still comprehensively used in China, we still adopt 16-race identification system in this review. Nine races including race 1, 2, 3, 4, 5, 6, 7, 9 and 14 have been found (Liu, 2005) in China. Among them, race 1 was predominant in Shandong, Hebei, and Shaanxi; race 3 was predominant in the northeast (including Heilongjiang, Jilin, Liaoning and Inner Mongolia); and race 4 predominated in Shanxi and Beijing city (Wu et al., 1982; Liu et al., 1984 and 1989a; Shang et al., 1989; Li et al., 1991; Lu et al., 2006). The total area of SCN-infected soybean increases each year, resulting in substantial yield losses. The controlling SCN methods include planting resistant cultivars, rotation with no host crops and bio-prevention with microorganism. Although no completely efficient way has been worked out for the SCN control, developing and planting of resistant cultivars is the most cost-effective and environmentally friendly method of controlling SCN.

\section{Major issues}

Resistance accessions to SCN had been screened worldwide, especially in USA and China. Over 100 resistance accessions were identified from plant introductions from the USDA Soybean Germplasm Collection (Chen et al., 2006), including PI 88788, Peking, PI 437654 etc. But 432 resistance accessions from Chinese soybean germplam (Ma et al., 2006), including Huipizhiheidou, Wuzaiheidou, Yingxianxiaoheidou, Harbinxiaoheidou etc, which were identified from less than 16000 accessions that taking $70 \%$ of the total Chinese soybean accessions. Only few of them have been used to discover resistance genes or QTLs. Until now, three recessive (rhg1, rhg 2 and $r h g 3$ ) and two dominant genes (Rhg4 and Rhg5) have been reported (Caldwell et al., 1960; Matson \& Williams, 1965; Rao-Arelli, 1994), and 151 QTL have been mapped from several accessions since 1994 (Zhang et al., 2010). Among them, one SCN locus refer to the resistant gene rhg1 was repeatedly mapped in almost all resistance accessions. The accessions with rhg1 were typically found to confer the greatest SCN resistance of any of the resistance QTLs. The Glyma18g02680.1 gene at the Rhg1 locus that encodes an apparent leucine-rich repeat transmembrane receptor-kinase (LRR-kinase). However, introduction of the gene (genomic promoter/coding region/terminator; Peking/PI 437654derived SCN-resistant source) into rhg1-SCN-susceptible plant lines carrying the resistantsource Rhg4+locus, provided no significant increases in SCN resistance. Studies in which expression of the LRR-kinase gene from different resistance accessions was either reduced or complemented did not reveal significant impacts on SCN resistance, suggesting that one or 
more other genes at the Rhg1 locus may be the primary determinant of differences in SCN resistance among different soybean types (Melito et al., 2010). However, one SNP haplotype and one InDeal markers developed from this genes were identified related to resistance and could be used (combine with Satt309) in the marker assistant selection (MAS) (Li et al., 2009; Nan et al., 2009). Therefore, it becomes more and more important to discover and incorporate map-based cloned gene in breeding program for developing resistant cultivars.

The narrow genetic base of SCN resistance is more apparent since the few resistant accessions used. Using SSR markers, Chen et al. (2006) clustered resistance accessions identified in USA into 7 clusters, which accounted for $42 \%$ of the total variation. Five of the 7 clusters seem to represent 5 distinct groups of resistance accessions to different SCN races. Moreover, the differences among clusters and among individual lines of different clusters were significant showed by the result of AMOVA. However, only few resistance accessions have been used extensively in the development of SCN-resistant cultivars. For example, in Midwest of USA, more than $90 \%$ of SCN resistance cultivars derived from only one source, PI 88788 (Concibido et al., 2004). Moreover, resistance to SCN is a multigenic trait, continuously growing the same resistant cultivar(s) may play a selection pressure on SCN that result in SCN to overcome resistance and shift to "resistance-breaking" races, such that resistant accessions may express resistance through mechanisms conferred by several different genes or alleles that render the cultivars susceptible (Riggs \& Schmidt 1988). Therefore, increasing available genetic diversity for SCN resistance in prior is critical for the long-term stability of host plant resistance as a control strategy for SCN. The major issues, including the shortage of resistant accessions and genes, complex of resistant mechanism and indefinite genetic base of resistant cultivars retard the development of the SCN breeding. A search for novel resistance accessions and novel resistance genes as well as new utilization and breeding methods based on "broad-based resistance" has become a major objective in soybean research.

It is generally accepted that soybean originated in China and abundant resistant accessions were resided in the Chinese gene pool. Soybean cultivation in China can be traced back to the ancient Huangdi period, as evidenced by the ancient books and archaeological discoveries. During the 4500 year planting history, a lot of soybean germplasm which exhibited highly phenotypic diversity and genetic diversity as a result of adaptation to complex climate and soil environments, as well as the human need were developed in China. Some of germplasm have been introduced into other major soybean-producing countries including the United States, Brazil, and Japan. These germplasm have emerged as valuable accessions for breeding SCN resistance cultivars. Niblack et al. (2002) assumed many "landraces" of soybean carried resistance to $H$. glycines, including populations that were genetically diverse since Chinese soybean farmers always selected soybean plants that provided acceptable levels of production in soils with a problem caused by $H$. glycines. Therefore, we introduced the progress on discovery and utilization of resistant accession in China in order to benefit the global soybean society for soybean improvement and production.

\section{Progress on genetics and breeding}

\subsection{Survey of SCN races in China}

SCN was mainly discovered in the two principal soybean production areas in China, Northeast and Huanghuai-Hai region (Table 1). Jaczevski firstly found SCN in the west part of Heilongjiang province in the northeast China in 1899. Until 1987, almost all regions in 
Heilongjiang province had the SCN problems except the five counties (Fuyuan, Huma, etc.). Among the SCN samples collected from 65 counties in Heilongjiang province, three races were identified using 16-race identification system. Race 3 was found in 63 samples, race 6 and race 7 were only in one sample respectively, suggesting that race 3 was the predominant race in Heilongjiang province (Liu et al., 1995). Except theses three races, race 1, 4, 5 and 14 were also discovered in Heilongjiang, whereas race 3 was still predominant (Shang \& Liu, 1989; Dong et al., 2008). Based on the degree of SCN occurrence, Heilongjiang was divided into three regions, in which the west region was severe infected area, the east (Three River Plain) was medium infected area and the rest area was light infected area (Liu et al., 1987). Within Jinlin province, Race 1 and 3 were predominant and race 5 and 7 were also discovered (Liu et al., 1992; Shang and Liu, 1989). Compared to Heilongjiang, Jilin and Inner Mengolia, the distribution pattern of SCN in Liaoning was much simple, there are only race 1 and 3 (Liu et al., 1985; Shang \& Liu, 1989).

Within the Huanghuai-Hai region in China, race 4 and 5 were firstly identified in the north region of Huai river (Zhang, 1988; Zhang et al., 1990), following by the race 4 in Beijing (Yan et al., 1995) and the race 7 in Shandong and Henan (Chen et al., 1988). In order to illustrate the major distribution pattern, a map of SCN races survey for a total of 38 sites in HuangHuai valleys was constructed (Lu et al., 2006). Three areas mainly infested with race 1 were identified, i.e. the area south-east to Jinan in Shangdong province, the area of northern Henan province and its border region to south of Hebei province, and the area of Luohe, Zhoukou of Henan province and Fuyang of Anhui province. Race 4 was predominant in Shanxi province, Beijing and the adjacent area of Henan, Shandong and Anhui provinces, and the delta of Huanghe River in Shandong province. Race 2 was mainly in Liaocheng, Dezhou of Shangdong province and Shijiazhuang of Hebei province, and Jiaozuo and Huojia of Henan province. Race 7 distributed in the west part of Jiaodong Peninsula of Shandong province and Kaifeng, Huaxian, Wenxian of Henan province. Race 5 was found and scattered in Hebei and Henan province. In this study, race 9 which was reported the first time in China was found in Shangqiu of Henan province. From the map of race distribution, race 1 and race 4 were the two predominant races in Huang-Huai regions ( $\mathrm{Lu}$ et al., 2006).

During 1992-1995, 12 immune and 28 resistant accessions to race 3 of SCN were evaluated by both natural infection in the field of different provinces and artificial inoculation. Among these accessions, only one accession shafted its phenotype from immune to resistant, confirming durable and stable resistance (Ma et al., 1996). However, the new SCN races were generated from the original races after forcibly propagation on resistant varieties for 912 generations reported in several previous studies. After retested on the differential hosts of soybean cyst nematode, the populations of the race 1 was acted as race 4 on Peking and Franklin, race 5 on Xiaolihei, race 6 on Tiefeng 18, race 9 on Fayette and Xiao li Black (Liu et al., 1998). The population of the race 3 was acted as race 2 on Harbinxiaoheidou, race 4 on Changlihei, race 14 on Peking, race 13 on Franklin while still as race 3 on Lee 68 (Liu et al., 1993). Recently, Yu et al. (2009) reported that the original SCN race 3 populations changed to race 6 after 10 generations of continuous planting resistant cultivars on Kangxian 1, Kangxian 2, Kangxian 3, Kangxian 4, and Kangxian 5; to race 10 on Huipizhiheidou; to race 14 on Peking; and to race 15 on Harbinxiaoheidou. Under production condition, the population of SCN race 3 was variable by planting the resistant soybeans for 13 years. According to Riggs \& Schmitt (1988) standard, the changed race was race 4 


\begin{tabular}{|c|c|c|c|c|}
\hline Race & Region & Province & City or County & Reference \\
\hline \multirow[t]{8}{*}{$\overline{\text { Race } 1}$} & \multirow[t]{3}{*}{ Northeast } & Jilin & $\begin{array}{l}\text { Chuangtu, Kangping, } \\
\text { Heishan, Zhangwu, Anshan, } \\
\text { Jinxian, Lvshun, Yixian, } \\
\text { Taian etc. }\end{array}$ & $\begin{array}{l}\text { Shang and Liu, } \\
1989\end{array}$ \\
\hline & & \multirow[t]{2}{*}{ Liaoning } & Yixian, lvshun & $\begin{array}{l}\text { Liu and Liu, } \\
1989\end{array}$ \\
\hline & & & Changtu & Liu et al., 1989 \\
\hline & \multirow[t]{5}{*}{$\begin{array}{l}\text { Huanghuai- } \\
\text { Hai }\end{array}$} & Hebei & Handan & Lu et al., 2006 \\
\hline & & Henan & $\begin{array}{l}\text { Huaxian, Heping, Lizhuang, } \\
\text { Xuchang, Linying }\end{array}$ & Lu et al., 2006 \\
\hline & & \multirow{4}{*}{$\begin{array}{l}\text { Jiangsu } \\
\text { Anhui } \\
\text { Shandong } \\
\text { Hebei }\end{array}$} & Xuzhou & Lu et al., 2006 \\
\hline & & & Fuyang & Lu et al., 2006 \\
\hline & & & Jinan & Lu et al., 2006 \\
\hline \multirow[t]{3}{*}{ Race 2} & \multirow[t]{3}{*}{$\begin{array}{l}\text { Huanghuai- } \\
\text { Hai }\end{array}$} & & Gaocheng & Lu et al., 2006 \\
\hline & & \multirow{2}{*}{$\begin{array}{l}\text { Henan } \\
\text { Shangdong }\end{array}$} & Jiaozuo, Huojia & Lu et al., 2006 \\
\hline & & & Dezhou & $\begin{array}{l}\text { Zheng and Yan, } \\
1997\end{array}$ \\
\hline \multirow[t]{4}{*}{ Race 3} & \multirow[t]{4}{*}{ Northeast } & \multirow[t]{3}{*}{ Heilongjiang } & $\begin{array}{l}\text { Heihe, Tonghe, Yichun, } \\
\text { Anda, Fujin, Jiamusi, Sunwu, } \\
\text { Boli, Suihua, Baiquan, } \\
\text { Huachuan, Hailin, Jiayin, } \\
\text { Xuke, Airport of Harbin, } \\
\text { Beian, Wudalianchi, } \\
\text { Shuangcheng, Kedong, } \\
\text { Suileng, Hailun }\end{array}$ & Dong et al., 2008 \\
\hline & & & Fuyu & $\begin{array}{l}\text { Liu and Liu, } \\
1989\end{array}$ \\
\hline & & & $\begin{array}{l}\text { Harbin, Jiamusi, } \\
\text { Mudanjiang, Zhaodong, Tieli } \\
\text { Jiamusi, Harbin, Mudanjiang, } \\
\text { Zhaodong, Tieli, Xinxun, } \\
\text { Mingshui, Daqing, Baoqing, } \\
\text { Suihua, Jixian, Bingxian, } \\
\text { Beian, Kedong, Gannan, } \\
\text { Fangzheng, Anda, Yaohe, } \\
\text { Shangzhi, Huacuan, Mulan, } \\
\text { Lanxi, Jidong, Fuyu, Linkou, } \\
\text { Mishan, Nengjiang, Keshan, } \\
\text { Tonghe }\end{array}$ & Liu et al., 1985 \\
\hline & & Jilin & $\begin{array}{l}\text { Baicheng, Zhenlai, Daan, } \\
\text { Fuyu, Zhaonan, Nongan, } \\
\text { Changling, Yushu, Panshi, } \\
\text { Jingyu }\end{array}$ & Liu et al., 1992 \\
\hline
\end{tabular}




\begin{tabular}{|c|c|c|c|c|}
\hline Race & Region & Province & City or County & Reference \\
\hline \multirow{16}{*}{ Race 4} & \multirow{16}{*}{$\begin{array}{l}\text { Northeast } \\
\text { Huanghuai- } \\
\text { Hai }\end{array}$} & Liaoning & $\begin{array}{l}\text { Shenyang, Fushun, Kaiyuan, } \\
\text { Fengcheng }\end{array}$ & $\begin{array}{l}\text { Liu and Liu, } \\
1989\end{array}$ \\
\hline & & Mengolia & Kezuoyouqi & $\begin{array}{l}\text { Liu and Liu, } \\
1989\end{array}$ \\
\hline & & \multirow{3}{*}{$\begin{array}{l}\text { Heilongjiang } \\
\text { Anhui }\end{array}$} & Anda & Dong et al., 2008 \\
\hline & & & Tangshan & Liu et al., 1989 \\
\hline & & & Tangshan, Haoxian, Suixi & Zhang, 1988 \\
\hline & & Beijing & Changping & Yan et al., 1995 \\
\hline & & Henan & Puyang, Zhengzhou, Tongxu, & Lu et al., 2006 \\
\hline & & Shandong & Heze & Lu et al., 2006 \\
\hline & & Shanxi & Taigu & Liu et al. 1989 \\
\hline & & & Fanshi, Wuxiang & Chen et al., 2001 \\
\hline & & & Taiyuan & $\begin{array}{l}\text { Liu and Liu, } \\
1989\end{array}$ \\
\hline & & & Fenyang, Linfen & Lu et al., 2006 \\
\hline & & Shangdong & Kenli & Liu et al. 1989 \\
\hline & & & Heze & Chen et al., 2001 \\
\hline & & Henan & Shangqiu & Chen et al., 2001 \\
\hline & & Jiangsu & Peixian & Chen et al., 2001 \\
\hline \multirow[t]{8}{*}{ Race 5} & Northeast & Jilin & Tongyu & $\begin{array}{l}\text { Shang and Liu, } \\
1989\end{array}$ \\
\hline & \multirow[t]{7}{*}{$\begin{array}{l}\text { Huanghuai- } \\
\text { Hai }\end{array}$} & \multirow[t]{3}{*}{ Anhui } & Mengcheng & Zhang, 1988 \\
\hline & & & Mengcheng & Zhang et al., 1990 \\
\hline & & & Mengcheng & Lu et al., 2006 \\
\hline & & Hebei & Changxian & Lu et al., 2006 \\
\hline & & Henan & Kaifeng, Huaxian, Wenxian & Chen et al., 2001 \\
\hline & & & Changge, Dazhou, Dongcun & Lu et al., 2006 \\
\hline & & Shandong & $\begin{array}{l}\text { Jiaoxian, Weifang, Gaomi, } \\
\text { Changyi }\end{array}$ & Chen et al., 2001 \\
\hline \multirow[t]{2}{*}{ Race 6} & \multirow[t]{2}{*}{ Northeast } & \multirow{4}{*}{$\begin{array}{l}\text { Heilongjiang } \\
\text { Mengolia } \\
\text { Jilin }\end{array}$} & Dedu & Liu et al., 1995 \\
\hline & & & & Chen et al., 1987 \\
\hline \multirow[t]{5}{*}{ Race 7} & \multirow[t]{5}{*}{ Northeast } & & Changling, Qianguo & Liu et al., 1992 \\
\hline & & & Changling, Qianguo & $\begin{array}{l}\text { Shang and Liu, } \\
1989\end{array}$ \\
\hline & & \multirow{3}{*}{$\begin{array}{l}\text { Helongjiang } \\
\text { Henan } \\
\text { Shandong }\end{array}$} & Qinggang & Liu et al., 1995 \\
\hline & & & Kaifeng, Huaxian, Wenxian & Chen et al., 1987 \\
\hline & & & $\begin{array}{l}\text { Jiaoxian, Weifang, Gaomi, } \\
\text { Changyi }\end{array}$ & Chen et al., 1987 \\
\hline Race 9 & $\begin{array}{l}\text { Huanghuai- } \\
\text { Hai }\end{array}$ & Henan & Shangqiu & Lu et al., 2006 \\
\hline $\begin{array}{l}\text { Race } \\
14\end{array}$ & Northeast & Heilongjiang & Anda & Dong et al., 2008 \\
\hline
\end{tabular}

Table 1. The distribution pattern of SCN in China 
and race 14, despite the race 4 did not find in Heilongjiang province before 2007 (Tian et al., 2007). These changes of races indicated that there might exist other races in an area with some predominant races since new SCN races were easily generated after long term of resistant varieties planting. These new races make resistant varieties become susceptible. For decreasing the damage of $\mathrm{SCN}$, the study conducted in the soybean field under continuous cropping (CS), wheat-soybean-wheat-soybean (WSWS) and wheat-maize-soybean (WMS) rotation systems in Heilongjiang. Total of 8 orders, 19 family and 43 genera nematodes were identified. Among them, 14 genera were affected by the crops stubbles and soil environment. Total number of soil nematodes was exhibited trends from low to high to low in CS and continuous higher in WSWS and WMS (Han et al., 2008). H. glycines would be acted as key species among all types of nematodes. The number of SCN including the number of cysts and all juveniles of different stages in soil and roots of soybean was notably increased in continuous cropping soybean field against rotation (Chen et al., 2007) because rotation can effectively decrease the SCN and other diseases in the soil.

\subsection{Survey of SCN resistant accessions in China}

Except the rotation with nonhost crops, planting resistant cultivars was another primary method for controlling SCN (Concibido et al., 2004). There SCN resistant accessions identification was beginning since the late seventies of last century in China. Wu et al. (1982) firstly reported four screened resistant accessions including Longkang SCN781, 782, 791 and 792 from 532 cultivated soybeans, 162 semi-wild soybeans and 115 wild soybeans by growing soybeans in pots with SCN infested soil. 11 varieties highly resistance to SCN were identified from 471 soybean accessions using field identification methods ( $\mathrm{Xu}$ et al., 2007). Liu et al. (1989a) screened 13 resistant accessions without race specific identification from more than 1000 soybean varieties, then further discovered 12 accessions resistant to race 1 , 13 accessions resistant to race 3 and 1 accession resistant to race 4 (Liu et al., 1989).

Since then, a set of resistant accessions have been identified focused on the predominant races on the different mainly production areas. Race 1 mainly distributed in Liaoning, Jilin, Henan and Shandong provinces. A total of 7772 soybean varieties form Huanghuai-Hai region, including Henan and Shandong province were firstly screened in the field infested with SCN and obtained 8 immune and 69 resistant accessions (Liu et al., 1991). Then a total of 10,117 accessions from different production regions were screened by Coordinative Group of Evaluation of SCN (1993) and 128 resistant and 16 immune accessions were identified. Among the 16 immune accessions, 13 were from Huanghuai-Hai region, including 9 from Shanxi, 2 from Hebei, 1 from Shandong and 1 from Shaanxi province. Moreover, all of 16 immune and 77 (68.8\% of total) resistant accessions were with black seedcoat. For race 2, 4 and 21 accessions were identified as immune and resistant respectively (Zheng \& Yan, 1997). For race 3, more than 10000 original landraces have been screened. A total of 88 local soybean varieties collected mainly from Liaoning province were screened by planting in the SCN infested plots and pots with infested soil. Of them, 17 resistant varieties to race 3 were identified (Liu \& Liu, 1985). Then 8183 cultivated soybean accessions were evaluated for their resistance to race 3 of SCN by both SCN infected soil and pot accessions during 1986 to 1990. Among them, 29 accessions showed immunity and 209 varieties showed resistant (Ma et al., 1991). Moreover Xu (1992) identified 48 accessions resistant from 1991 accessions. Although these studies identified a set of resistant accessions, the identification methods were not standard. Therefore, Coordinative Group of Evaluation 
of SCN was constructed on 1986. More than 10167 accessions in China were evaluated for their resistance to the races 1, 3, and 4 of $\mathrm{SCN}$, by growing them in the $\mathrm{SCN}$ infested soil and counting the number of white female cyst on the roots 5-6 weeks after planting. Accessions resistant and 30 accessions immune were identified (Coordinative Group of Evaluation of SCN, 1993). It was worth noting that all of immune accessions were from Huanghuai-Hai region. Ma et al. (1996) also identified 5 immune and 19 resistant accessions from 3355 cultivars. Of them, no immune and resistant accession was from South China. Li et al. (2008) also identified 8 resistant accessions from 394 soybean accessions from 7 provinces and cities during 2003 to 2006. Except for landraces, elite cultivars or lines were also screened. 36 released soybean cultivars from different locations of Heilongjiang province were evaluated for their resistance to race 3 of SCN during 1996 to 2000. The results showed that, 2 cultivars were resistant (Yu et al., 2001). And recently 7 lines resistant to SCN were identified from 71 new soybean elite lines (Yu and Wang, 2004).

Race 4 of SCN was mainly occurred and damaged the soybean production in HuanghuaiHai region. 11 highly resistant and 1 moderately resistant varieties to race 4 were first identified from 1920 soybean accessions, mainly landraces from Shanxi province (Li et al., 1987). Later, Li et al. (1991) screened 8240 soybean germplasms from six large areas of China and identified 9 high resistant accessions from Shanxi, Hebei and Shaanxi provinces. Zhang and Dai (1991) also identified seven resistant accessions to race 4 from 1800 soybean accessions from Huang-Huai area. Recently, Wang et al. (2005) screened 518 elite cultivar or lines and identified three resistant cultivars or lines. Coordinative Group of Evaluation of SCN (1993) also evaluated 10031 soybean accessions and identified 11 resistant accessions. However no immune materials were discovered until now.

Race 5 was mainly distributed in Henan, Shandong and Anhui province in Huanghuai-Hai region. Zhang \& Dai (1992) firstly screened 907 soybean accessions from Huanghuai-Hai region and identified seven accessions resistant to race 5 . Then, five accessions resistant to race 5 were identified from 904 soybean germplasms collected from Anhui province in Huanghuai-Hai region (Zhang, 1995). During 1992-1995, 3391 accessions from 21 provinces or cities in China were evaluated. Among the germplasms evaluated, 27 accessions showed resistant, it was $0.80 \%$ of the total evaluation number of accessions. Most of accessions resistant to soybean cyst nematode came from Hebei, Shandong, Shanxi, Chifeng, Jilin and Heilongjiang (Zhang et al., 1998).

Besides these identification focused on regional predominant races, some studies pay their attention on discovering the accessions resistant to multiple races. Liu et al. (1987) evaluated a total of 202 local soybean varieties collected mainly from Northeast China and identified four varieties resistant to both race 1 and 3 (Liu et al., 1987). Fu et al. (1989) evaluated ten resistant elite lines primary identified. Among them, 7 elite lines resistant to both race 3 and 4 and 3 were resistant to race 1, 3 and 4. Coordinative Group of Evaluation of SCN (1993) identified 4 accessions were resistant to the race1, 3, and 4 of SCN, including Wuzaiheidou, Huipizhiheidou, Longyaodaheidou and Wubaoheiheidou.

Until now, a total of $432 \mathrm{SCN}$ resistant germplasm were summarized based on the previous studies. These accessions came from 18 provinces, cities and autonomous regions (Table 2; Fig. 1a). The most of resistant accession $(89.35 \%)$ were from Huanghuai-Hai region. Among the provinces in Huanghuai-Hai region, Shanxi and Hebei ranked the top, taking $42.59 \%$ and $22.45 \%$ of the total resistant accessions respectively. Among the resistant accessions, most of them were resistant to race 1 and race 3 , taking $33.1 \%$ and $66.7 \%$, a few accessions were 
resistant to race 2, race 4 and race 5, taking $6.7 \%, 3.4 \%$ and $4.4 \%$ respectively; $89.8 \%$ accessions were landraces, indicating Chinese landraces was the large gene pool for identification of resistance to SCN.

\begin{tabular}{|c|c|c|c|c|c|c|c|}
\hline \multirow{2}{*}{ Origin } & \multicolumn{6}{|c|}{ No. of immunity and high resistant accessions } & \multirow{2}{*}{ Ratio (\%) } \\
\hline & Race 1 & Race 2 & Race 3 & Race 4 & Race 5 & Total & \\
\hline Northeast China & 9 & 5 & 16 & 0 & 5 & 29 & 6.71 \\
\hline Heilongjiang & 3 & 3 & 3 & 0 & 2 & 8 & 1.85 \\
\hline Jilin & 0 & 1 & 3 & 0 & 3 & 7 & 1.62 \\
\hline Liaoning & 3 & 1 & 10 & 0 & 0 & 11 & 2.55 \\
\hline Inner Mongolia & 3 & 0 & 0 & 0 & 0 & 3 & 0.69 \\
\hline $\begin{array}{l}\text { Huanghuai-Hai } \\
\text { region }\end{array}$ & 119 & 19 & 272 & 15 & 14 & 386 & 89.35 \\
\hline Anhui & 1 & 6 & 3 & 2 & 0 & 12 & 2.78 \\
\hline Beijing & 2 & 0 & 4 & 0 & 0 & 4 & 0.93 \\
\hline Gansu & 1 & 0 & 3 & 0 & 0 & 4 & 0.93 \\
\hline Hebei & 36 & 9 & 79 & 1 & 0 & 97 & 22.45 \\
\hline Henan & 9 & 0 & 7 & 0 & 0 & 14 & 3.24 \\
\hline Jiangsu & 4 & 3 & 0 & 0 & 0 & 7 & 1.62 \\
\hline Inner Mongolia & 3 & 0 & 7 & 0 & 0 & 9 & 2.08 \\
\hline Shanxi & 41 & 1 & 128 & 12 & 9 & 184 & 42.59 \\
\hline Shaanxi & 11 & 0 & 21 & 0 & 0 & 27 & 6.25 \\
\hline Shandong & 11 & 0 & 20 & 0 & 5 & 28 & 6.48 \\
\hline South China & 15 & 5 & 0 & 0 & 0 & 17 & 3.94 \\
\hline Guizhou & 6 & 0 & 0 & 0 & 0 & 6 & 1.39 \\
\hline Hubei & 9 & 3 & 0 & 0 & 0 & 9 & 2.08 \\
\hline Hunan & 0 & 1 & 0 & 0 & 0 & 1 & 0.23 \\
\hline Jiangxi & 0 & 1 & 0 & 0 & 0 & 1 & 0.23 \\
\hline
\end{tabular}

Table 2. The distribution pattern of Chinese soybean germplasm resistant to SCN

Since most of cultivated resistant accessions had one or more primary evolutionary traits, such as small seed, dark seed color, and viny growth habit etc, more number of resistant accessions were expected to be identified from wild soybeans. However, the frequency of resistant accessions in wild soybeans was much lower than in landraces. Wu et al. (1982) screened 162 semi-wild and 115 wild soybeans but no resistant source was discovered. Ma et al. (1996) also could not discover any accessions resistant to race 3 of SCN from 186 wild soybean accessions. Only Zhang et al. (1998) identified 3 accessions resistant to race 5 from 169 wild soybean accessions, mainly from Heilongjiang (130) and Beijing (21). It was 1. $78 \%$ of the total evaluation number of wild soybean. It was worth noting that all of them were from Heilongjiang province although no race 5 was discovered in this province. 

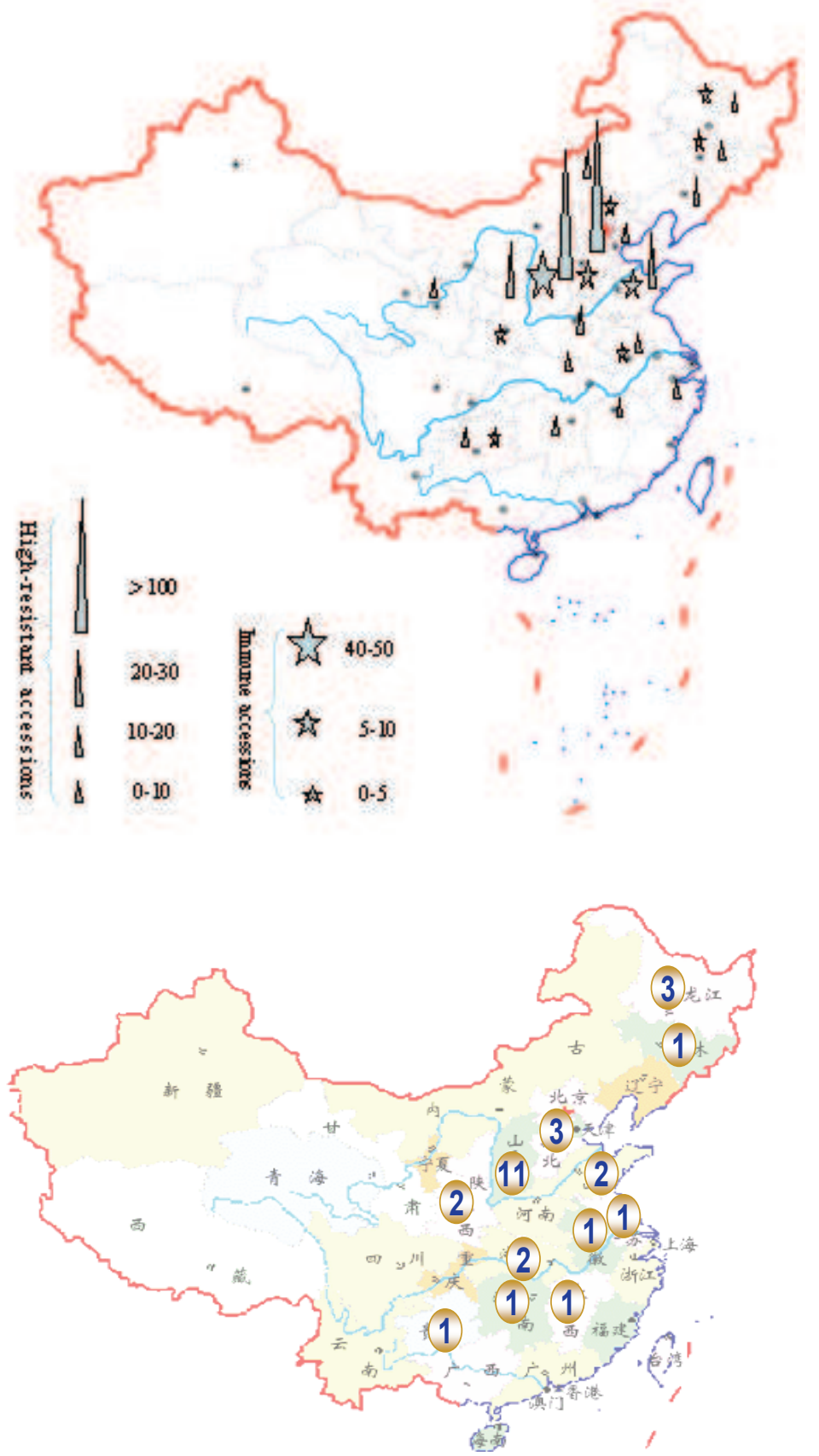

Fig. 1. The distribution of 432 resistant accessions (a) and Chinese SCN core collection (b). The number of resistant accessions in $b$ displays as blue letter. 


\subsection{Establishing applied core collection of resistance to SCN}

China has the most soybean germplasm in the world, but only about $1 \%$ of them have been used in soybean breeding program, which results in narrow genetic base for developing varieties (Qiu et al., 2009). By using four resistant and one susceptible standard soybean genotypes as differential lines (Golden et al. 1970; Riggs \& Schmitt, 1988), more than 400 resistant germplasm accessions have been identified since 1985, but a few of them has been analyzed at molecular level. In order to efficiently use Chinese SCN resistant accessions, the concept of core collection proposed by Frank and Brown (1984) was adopted. The primary applied core collection for SCN resistant was first constructed based on 9 quantitative traits, 5 qualitative traits and molecular marker analyses. The high resistant accessions were randomly selected within each group based on agronomic traits cluster analyses, but the accessions resistances to more SCN races were priority to be selected. This primary core collection consisted of higher ratio of accessions resistance to race $5(100 \%)$, race $2(92.5 \%)$ and race $4(80 \%)$ due to their low frequencies in the total, medium ratio $(53.57 \%)$ to race 1 , but the lowest (19.77\%) to race 3 . And the accessions except primary applied core collection were named as reserved collection. When compared to the whole collection, the primary core collection showed relatively high coincidence on the changing range of variation, mean value, of 5 qualitative traits including growth period (d), plant height $(\mathrm{cm}), 100$ seed weight $(\mathrm{g})$, protein content $(\%)$ and fat content $(\%)$. To compare the coincidence between primary core collection and the reserved collection, two set of 14 accessions from each of the reserved collection and primary applied core collection were analyzed with 50 SSR loci. 157 and 182 alleles were observed for each of the reserved and primary applied collections. The shared alleles between two collection were 141, indicating that primary applied core collection could represent $89.8 \%$ of the whole collection. Therefore this primary applied core collection for SCN resistance composed of 149 accessions could be better represent the whole resistant accession (Ma et al., 2006).

For establishing core collection, five selecting methods were compared based on the SSR genotyping data from 50 SSR loci, which approximately uniformly distributed on 20 soybean genetic linkage groups. (1) Random selection (RS): the samples were random selected without any relationship between different sampling ratios. (2) Containing random selection (CRS): After the first sample is completely random selected, it was used for further random selection. (3) Phenotype clustering selection (PCS): The selection was carried out based on the agronomic traits cluster analyses. (4) Resistant stratify clustering selection (RSCS): After stratify by resistant level, the selection was carried out within group based on SSR data. (5) SSR clustering selection (SCS): The selection was determined after cluster analyses based on the SSR data. Among five selection methods, both random methods of RS and CRS had lower reserved ratio of alleles than the other 3 stratifying methods of PCS, RSCS and SCS, in which RSCS and SCS were better than PCS. When sampling ratio was $27 \%$, allele reserved ratios for RSCS and SCS were more than $85 \%$, but not for the other 3 methods. When the sampling ratio was 20\%, RSCS and SCS had about $80 \%$ allele reserved ratio, but decrease to about $65 \%$ as the sampling ratio down to the $10 \% .19$ accessions were first selected since they were the same when compared RSCS to SCS, which taking $67.5 \%$ of the total alleles. Another 10 accessions were added to core collection after comprehensive comparison of similarity coefficients, agronomic traits, and resistance. Finally the SCN applied core collection consisted of 29 resistant accessions, which takes $78.06 \%$ of the total primary alleles (392) and represent $70.11 \%$ of diversity of the total collection. All 29 accessions consisted of 17 immune and 12 high resistant materials, which included 4 
accessions resistant to $3 \mathrm{SCN}$ races and $4 \mathrm{SCN}$ accessions resistant to $2 \mathrm{SCN}$ races and the rest 21 accessions resistant to only $1 \mathrm{SCN}$ race. Among them, 20 were landraces and the rest were bred lines. They were collected from 12 provinces of Heilongjiang (3), Jilin (1), Hebei (3), Shanxi (11), Shaanxi (2), Shandong (2), Jiangsu (1), Jiangxi (1), Anhui (1), Hubei (2), Hunan (1) and Guizhou (1) (Fig. 1b) (Ma et al., 2006).

\subsection{Cloning and expression of candidate resistant genes}

We know little about the SCN resistant mechanism for the complex interactions between soybean-nematode. The best-studied defence mechanism is based on the gene-for-gene resistance model through which plants with specific resistance genes specifically recognize pathogen genotypes carrying matching avirulence genes. Until now, Rhg4 and rhg1, the two major genes conferring resistance to SCN in soybean, were cloned (Meksem et al. 2005; Ruben et al. 2006). The Hs1pro-1 gene for resistance to the beet cyst nematode in sugar beet was expected to have resistant function to $\mathrm{SCN}$ in soybean. Therefore, the Beta procumbens Hs1 ${ }^{\text {pro-1 }}$ sequence (GenBank accession no. AAB48305.1) was used as a query probe to search the EST database at TIGR through the tblastn program, and an EST (TC219197) with substantial sequence similarity was obtained. According to the EST, a fragment which is $1,477 \mathrm{bp}$ with a full-length ORF of 1,314 bp was obtained and deposited in GenBank as GmHs1pro-1. The GmHs1pro-1, encodes a protein of 437 amino acid residues with Hspro1_N and Hspro1_C domains related to resistance to nematodes. Database searches revealed that GmHs1 pro-1, has $49 \%$ identity and $68 \%$ similarity with AKINbetagamma-interacting protein 1 from Arabidopsis thaliana, and $49 \%$ identity and $68 \%$ similarity with Hs1pro-1 from Beta procumbens over a stretch of 258 amino acids (189-432 in GmHs1pro-1) (Yuan et al., 2008).

Taking actin primers as control for the presence of equal amounts of cDNA, RT-PCR analysis revealed GmHs1pro-1 mRNA is more abundant in root, stem, and young leaf than it is in flower, pod, and old leaf. In pod, GmHs1 ${ }^{\text {pro-1 }}$ mRNA was almost undetectable (Yuan et al. 2008). Then the expression characteristics of candidate gene GmHslpro-1 on the resistant line Zhongpin03-5373 and susceptible cultivar Zhonghuang13 were performed using the realtime PCR technique to understand the relationship between the gene and resistance to SCN. The relative expression of the gene raised after $1 \mathrm{~d}$ vaccinating $\mathrm{SCN}$ race $4(\mathrm{SCN} 4)$ and it was 13.4 times higher than that of the control sample, the subsequent time points kept the upward and showed weakened after inoculated $6 \mathrm{~d}$. Analysis of variance showed that the relative expression of the gene was significant difference between inoculated and uninoculated at significant difference ( 0.05 or 0.01 level). It indicated $\mathrm{GmHslpro-1}$ might be induced to express in the conditions of SCN 4 infection (unpublished).

Lu \& Fang (2003) inoculated 2-day-old soybean seedlings of Huipizhiheidou with J2 of SCN race 4 . Thirty six cDNA clones corresponding to mRNAs with different abundances in SCN - infected (19 cDNAs) and uninfected (17 cDNAs) roots were identified using mRNA differential display technique. Six of them were recovered as plasmid clones that showed hybridization intensity differences in reverse dot blotting assay. These clones were discovered from soybean roots after inoculation. Their sequences had been registered in GenBank and were subjected to database comparisons with the aid of BLAST algorithm. Of then, A32 clone showed strong similarity to EST cDNA for coding MYB of Arabidopsis late elongated hypocotyls protein, one of cDNA from the library induced by tomato root nutrition deficiency and tomato cDNA of pseudomonas resistance expression library. 


\subsection{Genetic diversity of resistant germplasm 4.5.1 Molecular markers diversity}

To illustrate the distribution of alleles at SNPs loci in Chinese accessions and provides the information for utilization of SCN resistant accessions, 57 resistant soybean collections from both China and US were analyzed using SNPs at rhg1 and Rhg4 loci by using single based chain extension with a microsphere based assay. At both rhg1 and Rhg4 loci, 7 of 9 US resistant accessions and 37 of 49 Chinese resistant accessions had resistant genotypes too, taking $77.8 \%$ and $66.7 \%$ of the total accessions, respectively (Qiu et al., 2003).

Satt309 was the most closely linked $(0.4 \mathrm{cM})$ marker to rhg1, the most important gene resistant to SCN and usually used in the molecular marker assistant selection. Wang et al. (2003) analyzed 149 SCN immune or high resistant accessions, 495 susceptible accessions and 21 introductions from U. S.A using this SSR marker. A total of 6 alleles were identified, and found 1 novel allele between 134bp and 149bp. The two accessions carried this novel allele were immune and moderate resistance to race 1 separately. Most susceptible accessions, taking $92.13 \%$ of the total, had one of $125 \mathrm{bp}, 134 \mathrm{bp}$ and $149 \mathrm{bp}$ alleles; while most immune or multi-resistant accessions were identified to have $128 \mathrm{bp}$ or $134 \mathrm{bp}$ allele. 14 of 16 accessions with 128bp allele came from Shanxi province, which suggested that Shanxi province maybe was the origin of accessions with $128 \mathrm{bp}$ allele.

\subsubsection{SNP discovery and diversity analysis of candidate resistant genes}

By sequencing SCN related gene GmHs1pro-1 of 8 landraces, 12 cultivars and 23 wild soybeans in addition to WF7, fourteen single-nucleotide polymorphisms (SNPs) were detected, among which 3 were singletons and 11 were informative sites, resulting one SNP every $105.5 \mathrm{bp}$. Of the $14 \mathrm{SNPs}, 6$ were nonsynonymous (the encoded amino acid was altered by the SNP), 6 were synonymous (the encoded amino acid was not altered by the $\mathrm{SNP}$ ), and 2 occurred in the $3^{\prime}$-untranslated region (3'-UTR). Six nucleotide mutation types (T/A, C/A, C/T, T/G, G/A, G/C) were detected; eight were involved in transitions, and six were transversions with a transition- transversion ratio of $4 / 3$. Of 11 SNPs in wild soybeans, five were not found in landraces or cultivars, nine of three SNPs in landraces were unique, whereas there was none for three SNPs in cultivated soybean. Two parameters of $\Pi$ and $\theta$ values were calculated to describe sequence diversity of $G m H s 1$ pro-1, which were 0.00168 and 0.00218 among 43 accessions. Among the three populations, landraces had the highest diversity with $\Pi=0.00249$ and $\theta=0.00235$, followed by wild soybeans, while cultivars had the lowest diversity with $\Pi=0.00031$ and $\theta=0.00065$ (Yuan et al., 2008).

The sequence of major SCN candidated gene rhg1 were compared in aligned 4995 nucleotides. A total of 42 polymorphisms among eight soybean genotypes consisted of 37 SNPs and 5 InDels. Among the 37 SNPs, 11 (29.7\%) were singleton variable loci that found in only one genotype, and $26(70.3 \%)$ were parsimony informative loci found in at least two genotypes. No SNPs were detected in the $5^{\prime}$-noncoding region, nine were in exon1, one in the intron, two in exon 2 and 25 in the $3^{\prime}$-noncoding region. Seven of the 11 SNPs in the coding regions led to changes in amino acid codons (six in exon1 and one in exon2). Moreover, more than 30 SNPs were detected from the sequence comparison of Chinese soybean accessions (Li et al., 2009).

A total of 44 single nucleotide polymorphisms (SNPs) including 43 single base changes and 1 DNA insertion-deletions (Indels) were identified from Rhg4 sequence. Sequence diversity analysis on 24 Chinese cultivated and wild soybean showed $\Pi=0.00203$ and $\theta=0.00348$ for 
Rhg4. Comparison with two G. max populations of landraces and cultivars, G. max had the highest diversity $(\Pi=0.00218$ and $\theta=0.00283$ ) (Yuan et al., 2007).

These SNPs from rhg1 and Rhg4 were used to clarify the difference of genetic diversity and linkage disequilibrium (LD) level between G. max and G. soja (Li et al., 2009). The results indicated that G. max population, consisted of cultivated soybean mini-core collection and modern cultivars, had a higher LD levels $\left(\mathrm{R}^{2}\right.$ value is 0.216$)$ than $G$. soja population. Within G. max population, two specific LD regions were formed for each gene.

\subsection{SNP markers development and utilization}

Six AS-PCR (Agarose gel-based Co-dominant Allele-Specific) markers and 5 FLDAS (Fragment Length Discrepant Allele Specific) PCR markers were developed from rhg1 and Rhg4 respectively ( $\mathrm{Li}$ et al., 2009; Yuan et al., 2007). All of them behaved co-dominantly except locus of 2564G>A that was dominant. The Actin gene (sequence number in GenBank: V00450) was used as a positive control in the multiplex PCR. Among the six selected SNPs for developing AS-PCR marker in rhg1, three were in exon1, two were in exon2 and one was in the $3^{\prime}$-noncoding region. Of the five SNPs in the coding regions, two $(689 \mathrm{C}>\mathrm{A}$ and $757 \mathrm{C}>\mathrm{T}$ ) were located between the N-terminal signal peptide domain and the leucine rich repeat domain; the others were located in the serine/threonine kinase domain. Four SNPs (at positions 689, 757, 2564 and 3995) form one haplotype present in five resistant genotypes (Peking, PI437654, Sangutiaoheidou, Xiaolimoshidou and Huipizhiheidou), and another haplotype in the susceptible genotypes Suinong 14 and Guxin. The SNP at position 2233 characterized all resistant genotypes except Huipizhiheidou. Finally, the SNP at position 2868 was present in all genotypes except You1298, the line with moderate resistance only to race5.

The six SNPs from rhg1 formed nine distinct haplotypes among the 70 genotypes. The haplotypes (HAPs) from different cultivars were displayed in a neighbor-joining tree. Genotypes with HAP 1 to HAP 6 clustered in one group, and HAP 7 to HAP 9 in another, supported by a bootstrap value of $84 \%$. The haplotype in G. soja and G. max was the same as that in several other SCN susceptible landraces and cultivars. All known resistant genotypes (23) were included in the first cluster, while the eight susceptible genotypes were all placed in the second cluster. The frequency of different haplotypes ranged from $1.4 \%$ to $24.3 \%$. Of the nine haplotypes, HAP9 (A-T-A-A-T-C) was the most common and HAP7 (A-T-G-G-C-A) was unique being only present in Lee. The nucleotide diversity for the six SNP loci among the 70 genotypes was 0.449 and haplotype diversity was 0.841 . The number of haplotypes detected was much less than 64 haplotypes as expected when assuming that the six loci are in Hardy-Weinberg equilibrium with each other. This may indicate that natural selection or directional selection for resistance to SCN has been occurring.

Using 5 FLDAS makrers, the diversity of Rhg4 and its distribution in soybean germplasms was illustrated (Yuan et al., 2007). Rhg4 had high diversity, and higher diversity was found in G. max than that in G. soja. Distribution of the 5 SNP sites mentioned above between resistant and susceptible accessions to $\mathrm{SCN}$ indicated that Rhg4 takes a role in soybean resistance to the race1, 3 and 4 of SCN.

\subsection{SCN genetic analysis and QTL discovery 4.7.1 Genetic linkage mapping}

Six resistant accessions were used to clarify the genetic mechanism of resistance and discover QTL resistant to SCN since 1992 (Table 3). Wu et al. (1992) crossed the SCN 


\begin{tabular}{|c|c|c|c|c|c|}
\hline Cross & $\begin{array}{c}\text { Type of } \\
\text { population }\end{array}$ & Race & Locus & $\begin{array}{l}\text { Marker or } \\
\text { region }\end{array}$ & Reference \\
\hline Hefeng $25 \times$ Kangxian $2^{*}$ & $\mathrm{~F}_{2}$ & 3 & - & $\begin{array}{l}\text { Satt163-Satt309 } \\
\text { Sat440-Satt148 }\end{array}$ & $\begin{array}{c}\text { Yang et al. } \\
\text { (2010) }\end{array}$ \\
\hline \multirow{2}{*}{ Liaodou10×Xiaoliheidou* } & \multirow{2}{*}{$\mathrm{F}_{2}$} & 1 & - & Satt187 & $\begin{array}{c}\text { Wang et al. } \\
\quad(2007)\end{array}$ \\
\hline & & 3 & - & S11700 & \multirow[t]{4}{*}{$\begin{array}{c}\text { Wang et al. } \\
\text { (2005) }\end{array}$} \\
\hline \multirow{7}{*}{ Essex $\times$ Huipizhiheidou* } & \multirow{7}{*}{$\mathrm{BC}_{1}$} & 1 & rhgR1-1 & $\begin{array}{l}\text { Sat_210- } \\
\text { Sat_168 }\end{array}$ & \\
\hline & & 1 & rhgR1-2 & $\begin{array}{l}\text { Sat_168- } \\
\text { Sat_141 }\end{array}$ & \\
\hline & & 1 & rhgR1-3 & Satt672-Satt413 & \\
\hline & & 4 & rhgR4-1 & $\begin{array}{l}\text { Satt275- } \\
\text { Sat_210 }\end{array}$ & \multirow[t]{4}{*}{$\begin{array}{l}\text { Lu et al. } \\
\text { (2006) }\end{array}$} \\
\hline & & 4 & rhgR4-2 & $\begin{array}{l}\text { Sat_168- } \\
\text { Sat_141 }\end{array}$ & \\
\hline & & 4 & rhgR4-3 & $\begin{array}{l}\text { Satt442- } \\
\text { Sat_401 }\end{array}$ & \\
\hline & & 4 & rhgR4-4 & $\begin{array}{l}\text { Sat_334- } \\
\text { Satt181 }\end{array}$ & \\
\hline \multirow{3}{*}{ Jindou23 $\times$ Huipizhiheidou* } & \multirow{3}{*}{$\mathrm{F}_{2}$} & & $\begin{array}{c}\text { rhgR4a- } \\
1\end{array}$ & BSC-Satt632 & \multirow{3}{*}{$\begin{array}{c}\text { Meng et al. } \\
\quad(2003)\end{array}$} \\
\hline & & 4 & $\begin{array}{c}\text { rhgR4a- } \\
2\end{array}$ & $\begin{array}{l}\text { Satt632- } \\
\text { Sat_162 }\end{array}$ & \\
\hline & & & $\begin{array}{c}\text { rhgR4a- } \\
3\end{array}$ & Satt610-Satt309 & \\
\hline Yingxianxiaoheidou* $\times$ Jindou23 & $\mathrm{F}_{2}$ & 4 & - & Satt038, ISSR81 & $\begin{array}{c}\text { Fang et al. } \\
\text { (2002) }\end{array}$ \\
\hline
\end{tabular}

Table 3. List of crosses and identified molecular markers associated with SCN reported resistant soybean with susceptible cultivars. They discovered all of $F_{1}$ plants were susceptible in populations derived from four types of crosses (Susceptible X Resistant, Resistant X Susceptible, Susceptible X Susceptible, and Resistant X Resistant). The genetic analysis indicated that $F_{2}$ resistance segregation was controlled by three pairs of recessive genes. Among the resistant accessions analyzed, two local landraces Yingxiangxiaoheidou 
and Huipizhihedou were detailed analyzed in China. The inheritance of Yingxiangxiaoheidou which was resistant to race 1, 3 and 4 was analyzed using the $F_{2}, F_{3}$ population of ZDD2226 (Yingxiangxiaoheidou) $x$ Jindou 23. The results showed that the highly resistance to race 4 of SCN in ZDD2226 was controlled by 1 or 2 couples of recessive allele in $F_{2}$ population (Wang et al., 2001). The resistance of Yingxianxiaoheidou to SCN race 1 was controlled by recessive genes and the same resistant genes were also in Peking by the populations of $\mathrm{BC}_{1} \mathrm{~F}_{2}$ lines in crosses of PI88788 $\times$ Yingxianxiaoheidou and Peking $\times$ Yingxianxiaoheidou. There was 1 pair of gene difference between PI88788 and Yingxianxiaoheidou (Wang et al., 2004), indicating the different genetic mechanisms among various SCN races and crosses. For localize resistance genes associated with race 4 of SCN, an $\mathrm{F}_{2}$ population derived from Yingxiangxiaoheidou (ZDD2226) X Jindou 23 were screened by SSR and ISSR molecular markers with the method of Bulked Segregant Analysis. Two molecular markers, Satt308 and ISSR811 were discovered associated with resistance in Yingxiangxiaoheidou to race 4.

Race 1 and race 4 are predominant races of soybean cyst nematode (SCN) in Huang-Huai Valleys in China. The soybean landrace Huipizhiheidou, was recognized as an elite resistance source with mutiple races of race 1, 2, 3, 4 and 5 for mapping QTLs conferring resistance to race 1 and race 4 . In 2003, a population of $253 \mathrm{~F}_{2: 3}$ families which was generated from a cross between Huipizhiheidou and Jindou 23 were used for molecular marker identification. Three QTLs were mapped to soybean linkage A and G, respectively, conferring resistance to SCN race 4 . Of them, one QTL mapped on lingkage group $\mathrm{G}$ and is $2.0 \mathrm{cM}$ away from Satt610 marker, named rhg-R4g1 and explains $15.87 \%$ of the phenotypic variation. Two QTLs mapped on LG A, one (rhg-R4a1) is $0.2 \mathrm{cM}$ away from Sat_162 and another is $1.6 \mathrm{cM}$ (rhg-R4a2) from BSC marker. They could explain $11.31 \%$ and $6.15 \%$ of the total phenotypic variation respectively (Meng et al., 2003). In 2006, a mapping population with $114 \quad \mathrm{BC}_{1} \mathrm{~F}_{1}$ plants of the backcross (Essex $\times$ Huipizhiheidou) $\times$ Huipizhiheidou was established and mapped 3 QTLs conferring resistance to SCN race 1 and 5 QTLs conferring resistance to SCN race 4. Of the QTLs related to race 1, 2 (rhgR1-1 and rhgR1-2) located on linkage group G and 1 (rhgR1-3) on linkage group D2. They explained $22.4 \%, 21.8 \%$ and $6.2 \%$ of the total phenotypic variation respectively, while rhgR1-1 and rhgR1-3 cosegregated with Sat- 210 and Satt672, respectively. Of the QTLs related to race 4, rhgR4-1 (within Satt275-Sat-210) and rhgR4-2 (within Sat-168-Sat-141) were located on linkage group G, rhgR4-3 (within Satt442-Sat-401) and rhgR4-4 (within Sat-334-Satt181) were located on linkage group $\mathrm{H}$, and rhgR4-5 within Satt652-Sat-301 was located on linkage group L. They explained $22.8 \%, 28.9 \%, 12.0 \%, 10.5 \%$ and $5.9 \%$ of the total phenotypic variation respectively, while rhgR4-2 and rhgR4-5 co-segregated with Sat-168 and Satt652, respectively. Suggested that different QTL systems conferred resistance to race 1 and race 4 in Huipizhiheidou (Lu et al., 2006).

\subsubsection{Association mapping}

In order to discover molecular markers related to SCN resistance, 130 SSR markers were used to analyze 41 elite soybean lines from the crosses of Hartwig $\times$ Jin 1261, Hartwig $\times$ Jin 1265 and Hartwig $\times$ Jin 1267 (Yuan et al., 2008) since Hartwig and Jin 1261, Jin 1265 or Jin 1267 had different resistance genes to SCN 4, with genetic similarity of 0.362 . Using association mapping method, twenty-two SSR markers from 11 linkage groups were identified as associated with resistance to SCN 4 . It has been found that there was at least a 
new resistance gene in Jin strains on linkage group D1b. Moreover, these resistant lines to SCN 4 was effectively identified using two SSR markers of Satt684 and Sat_400.

Except above inbred lines, natural population were also used for association mapping in identifyting resistance markers. LD analysis in a natural population consisted of 70 resistant and susceptible soybean accession showed that the average values of $\mathrm{D}^{\prime}$ and $\mathrm{r}^{2}$ for pairwise comparisons of six SNP marker loci from rhg1 were 0.815 and 0.403 , respectively. Most $(60 \%)$ of the pairwise loci were in significant linkage disequilibrium $(\mathrm{P}<0.0001)$ and the average value of $\mathrm{D}^{\prime}$ and $\mathrm{r}^{2}$ for the nine significant pairwise loci were 0.869 and 0.587 , respectively. The pair $689 \mathrm{C}>\mathrm{A}$ and $757 \mathrm{C}>\mathrm{T}$, at close distance of each other and adjacent to the LRR domain (556-676), had the strongest linkage disequilibrium with the highest $\mathrm{D}^{\prime}$ and $\mathrm{r} 2$ values. No recombination event was detected between them. Pairs of alleles involving the $2868 \mathrm{~T}>\mathrm{C}$ locus and the other loci were not significantly in LD, as was the case for loci $2233 \mathrm{G}>\mathrm{A}$ and $3995 \mathrm{~A}>\mathrm{C}$. The minimum number of recombination events separating these groups was $4(\mathrm{Rm}=4)$ detected between $757 \mathrm{C}>\mathrm{T}$ and $2233 \mathrm{G}>\mathrm{A}, 2233 \mathrm{G}>\mathrm{A}$ and $2564 \mathrm{G}>\mathrm{A}$, $2564 \mathrm{G}>\mathrm{A}$ and $2868 \mathrm{~T}>\mathrm{C}$, and $2868 \mathrm{~T}>\mathrm{C}$ and 3995A $>\mathrm{C}$ ( $\mathrm{Li}$ et al, 2008). The frequencies of $689 \mathrm{C}$, 757C, 2564G and 3995A in $23 \mathrm{SCN}$ resistant genotypes were 1.00, 1.00, 1.00 and 0.96, respectively. SNP 2564G was also observed in the unique haplotype of susceptible genotype Lee, but the other four were absent in any of the eight genotypes comprising the susceptible population. Therefore, 689C, 757C, 2564G and 3995A can be considered as resistanceassociated SNPs. The haplotype of Heidou 2, resistant to race 2, was identical to the others in the resistant group at the first three SNPs, but had SNP 3995C. The distribution of haplotype $689 \mathrm{C}-757 \mathrm{C}$ in the 23 resistant and 8 susceptible groups was compared with the distribution of alleles present at the Satt309 where a total of five alleles with estimated length of 125bp, 128bp, 131bp, 134bp and 149bp have been detected. In previous studies (Cregan et al. 1999; Wang et al. 2003), alleles 128 bp and 134 bp were considered as markers for 'resistance' alleles, and alleles $131 \mathrm{bp}$ and allele $149 \mathrm{bp}$ as markers for 'susceptibility' alleles. In the present study, alleles $128 \mathrm{bp}$ and $134 \mathrm{bp}$ coincided with the 689C-757C haplotype, and alleles $131 \mathrm{bp}$ and $149 \mathrm{bp}$ coincided with the 689A-757T haplotype. The 125 bp allele occurred in single genotypes of resistant as well as susceptible genotypes in previous studies, but our results show that the SNPs on $689 \mathrm{C}>\mathrm{A}$ and $757 \mathrm{C}>\mathrm{T}$ can successfully separate the resistant (for example, PI88788) from the susceptible genotypes (for example, Lee). Therefore, our haplotypes may be more efficient than Satt309 in markerassisted selection (MAS) (Li et al., 2009).

\subsection{Cultivar development resistance to SCN in China}

Since 1978, the new resistant accessions with yellow seed coat and larger seeds (over 15 grams of 100 seeds weight) had been incorporated into breeding program by crossing and back crossing (Liu et al., 1987). Until now, more than 100 SCN resistant cultivars or lines have been developed in China. In Shandong province, using Beijingxiaoheidou and Haerbinxiaoheidou as the resistant parents, a series of soybean cultivars or lines resistant to SCN such as Qihuang 25, 28 and 29, Qichadou 1, and 2, Gaozuoxuan1hao, Yuejin8hao, 91724, 93746, 93747, and 93748 were bred by artificial hybridization to introduce resistant genotype (Hao et al., 2000). In Beijing, Zhonghuang8, 9, 11, 12, 13 and 17, Zhonghuang57 and Kefeng were developed. By integrating resistant plant introductions with Chinese resistant lines, some new lines and cultivars were developed that had multiple race resistance. For example, 41 elite soybean lines were developed from the crosses of Hartwig $\times$ Jin1261, Hartwig $\times$ Jin1265 and Hartwig $\times$ Jin1267. The index of parasitism (IP) of 
these lines differ largely with a range from 0 to 83.2, even the IP of their all of parent were lower than 3. Among them, 31 lines from different crosses were identified as resistance. Among them, 7 yellow seedcoat cultivars were selected because they posses high yield and high resistance or immunity to race 1 and 4 of SCN (Liu et al. 2008). Jin1263 and 1268 were also develop in Shanxi province except Jin1261, Jin1265 and Jin1267. In Heilongjiang province, the SCN resistant materials were crossed with the local varieties to select the resistant line, such as Kangxian 1, 2, 3, 4 ,5 and 6, Qingfeng1hao, Nenfeng15, Dongnong43, Kenfeng1hao, Ken86-6331, Qingkang83219, Qingkang8408-2, 84-783, 84-793, 84-919 etc. In Jilin province, Jinlin23, 32 and 37, Bainong5, 8 and 9hao were developed (Wang et al., 2002; Wu et al., 1989; Xu et al., 2003).

Although a set of soybean cultivars and lines resistant to SCN were bred, they still can not meet the demands of soybean production. Among over 1500 modern cultivars have been developed in China, less $10 \%$ of the cultivars have the characteristics of resistance to SCN. Indicated that it is more difficult to develop SCN resistant lines than other elite lines elite lines (Yu and Wang, 2004). By screened 193 cultivars from the soybean regional test in 20042007 for the resistance to race 1 of SCN, Wang et al. (2009) found only 25 cultivars with moderate resistance and no highly resistant cultivar at all. Therefore, it is urgent to enhance the new resistant germplam for breeding new resistant cultivars for sustainable soybean production.

\section{Challenging}

The advances of resistance identification, QTLs or genes discovery, resistant cultivar development in China are not only benefiting the soybean production in China but the worldwide also. A lots of QTLs has been found, but few of them has been cloned and utilized for MAS selection of SCN resistant cultivars. There are several difficulties, including the more genes involved in the interaction between soybean and cyst nematode, minor effect of each genes as well as SCN race population shifting. Moreover, SCN resistant germplasm enhancement also face the challenge because most of soybean resistant accessions identified were dark seed coat, smaller seed size, and vinyl for growth habits. These unfavorable characteristics also need to be overcome for developing resistant cultivars in soybean. Therefore, we should strengthen related basic research, such as cloning resistance genes at genome wide level based on integrating resequencing data, expression files, proteomics data as well as phenomics dada. Released genome sequences for both G. max (Schmutz et al., 2010) and G. soja (unpublised, personal communication) and resequenced one resistant accession (Huipizhiheidou) (unpublised) provide more information for clarifying the genetic mechanism of SCN resistance and discover gene controlling resistance using methodologies emerged recently, such as single feature polymorphism analysis, Illumina Goldengate SNP genotyping, and de novo SNP discovery via RNA-Seq analysis of next-generation sequence data. In addition, expression pattern analysis and function variation of new genes identified using transgenic technique will provides insight into soybean cyst nematode parasitism gene functions and interactions with host soybean. In addition to the analysis methodologies, developing mutants and the near SCN isogenic lines might be the efficient ways for gene discovery for avoiding genetic background influence. On the other hand, we should explore new breeding methods to efficiently utilize the resistant accessions and accelerate the advancement of breeding for soybean production. 


\section{Acknowledgments}

This research was supported by the State High-tech (863) (No.2006AA10A110, 2006AA10Z164, 2006AA10A111), the National Natural Science Foundation of China (No.30490250 and 30471096), State Key Basic Research and Development Plan of China (973) (2010CB125903), and International Science and Technology Cooperation and Exchanges Projects (No. 20061773).

\section{References}

Caldwell, B.; Brim, C.; \& Ross, J. (1960). Inheritance of resistance to soybean to the cyst nematode, Heterodera glycines. Agron. J, 52: 636-636

Coordinative group of Evaluation of SCN. (1993). Evaluation of soybean germplasm for resistance to race 1,3 and 4 of the soybean cyst nematode. Soybean Science,12 (2): 91 99, 1000-9841

Chen, L.; Zhu, Y.; Liu, B. \& Duan, Y. (2007). Influence of continuous cropping and rotation on soybean cyst nematode and soil nematode community structure. Acta Phytophylacica Sinica, 34(4): 347-352, 0577-7518

Chen, Y.; Wang, D.; Arelli, P.; Ebrahimi, M.; \&Nelson, R. (2006). Molecular marker diversity of SCN-resistant sources in soybean. Genome, 49(8): 938-949

Chen, P.; Zhang, D.\& Chen, S. (1988). First report on a new physiological race (race 7) of soybean cyst nematode (Heterodera glycines), Scientia Agricultura Sinica, 20: 94, 05781752

Concibido, V.; Diers, B. \& Arelli, P. (2004). A decade of QTL mapping for cyst nematode resistance in soybean. Crop Science, 44 (4): 1121-1131, 0011-183X

Cregan, P.; Mudge, J.; Fickus, E.; Denny, R.; Danesh, R.; \& Young, N. (1999). Two simple sequence repeat markers to select for soybean cyst nematode resistance conditioned by the rhg1 locus. Theor Appl Genet 99: 811-818, 0040-5752

Dong, L.; Xu, Y.; Li, C.; Pan, F.; Xie, Y.; Han, Y.; Teng, W. \& Li, W.(2008). Cystden sity and subspeicies idntification of soybean cyst nematode in Heilongjiang Province. Chinese J of Oil Crop Sciences, 30(1):108-111, 1007-9084

Fang, X.; Wang, J.; Wan, Y.; Liu, X.\& Chen S.(2002).SSR\&ISSR molecular tagging of gene conferring resistance to race 4 of soybean cyst nematode(SCN) for soybean ZDD2226 in China. Journal of Agricultural Biotechnology,10 (1): 81-85, 1674-7968

Frankel, O.\& Brown, A. (1984). Current plant genetic resources -a critical appraisal. In: Genetics:New Fronetiers(vol.IV). New Delhi, India: Oxford and IBH publishing

Fu, J.; Yu, D.; Nian, H. \&Liu, Y.(1989).The resistance of soybean lines to soybean syst nematode races. Journal of Jilin Agricultural Sciences, 4: 36-38, 1003-8701

Golden, A.; Epps, J.; Riggs ,R.; Duclos, L.; Fox, J.\& Bernard, R. (1970). Terminology and identity of intraspecific forms of the soybean cyst nematode (Heterodera glycines).Plant Disease Report, 54, 544-546, 0191-2917

Hao, X.; Jiang, H.; Gao, J. \&Wu, J. (2000). Introduction of resistant gene and production of high yielding materials resistant to soybean cyst nematode for summer soybean. Shandong Agricultural Sciences, 3: 4-7, 1001-4942

Han, X.; Xu, Y.; Pan, F. \& Li, C.(2008). Community structure of Soil nematodes in soybean fields under different rotation systems. Soybean Science, 27(1): 118-123, 1000-9841 
Li, N.; Li, M.; Yan, X.; Sun, X.; Ma, J.; Zhang, Z.; Han, X. \& Wang, M. (2008). Evaluation of resistance of soybean germplasm to race 3 of soybean cyst nematode. Journal of Jilin Agricultural Sciences, 33(2): 34-35, 1003-8701

Li, W.; He, C. \& Tian, B. (1991). Identification and distribution of soybean cyst nematode in Henan province. ACTA Agric Boreali-Sin , 6, (suppl.) ,111-114, 0046-225X

Li, Y.; Wang, Z.; Jiao, G. \& Chang, R.(1991).Studies on resistance of soybean germplasm resources to race 4 of soybean cyst nematode. Scientia Agricultura Sinica, 24(5): 6469, 0578-1752

Li, Y.; Wang, Z. \& Wei, B.(1987).The screening and utilization of new resistant sources to soybean cyst nematode race No.4. Soybean Science, 6(4): 291-298, 1000-9841

Li, Y.; Yuan, C.; Zhang, C.; Li,W.; Nan, H.; Chang, R. \& Qiu, L.(2009).Genetic variation of SNP loci based on candidate gene for resistance to soybean cyst nematode. Hereditas, 31(12): 1259-1264, 0253-9772

Liu, H.; Shang, S.; Huo, H.; Wu H.; Yao, Z. \& Li ,X. (1987).Present status of occurrence, injury and research of soybean cyst nematode in Heilongiiang province. Soybean Science, 6(2): 141-148, 1000-9841

Liu, H.; Shang, S.; Huo, H.; Wu H.; Yao, Z. \& Li ,X. (1985). Study on physiological race of soybean cyst nematode(Heterodera glycines) .Soybean Science, 4(1): 131-136, 1000-9841

Liu, H.; Shang, S.; Huo, H. \& Wu, H. (1989a). Resistance of soybean varieties to races 1, 3 and 4 of soybean cyst nematode. Soybean Science, 8(1): 113-114, 1000-9841

Liu, H.; Shang, S. \& Huo, H. (1989b). Identification of races of soybean cyst nematode in Heilongiiang province. Chinese Journal of Oil Crop Sciences, 1: 60-62, 1007-9084

Liu, H.; Shang, S.; Zhen, H. \& Huo, H. (1995). Study on distribution of physiological race of soybean cyst nematode (Heterodera Glycines) in Heilongjiang province. Soybean Science, 14(4): 330-333, 1000-9841

Liu, PY.(2005).Advances in Study of Screening and Utilization for Antigen to Soybean Cyst Nematode. Heilongjiang Agric Sci, 6: 44-47, 1002-2767

Liu, W.; Liu, Y\& Duan, Y.(1991).Test of soybean germplasm form Huang, Huai and Hai river valley for resistance to race 1 of soybean cyst nematode. Soybean Science, 10(4): 327-329,1000-9841

Liu, W.; Liu, Y.; Duan, Y.\& Wu, A.(1993).Selection effect of resistant soybeans on the race 3 of soybean cyst nematoude Heterodera Glycines. ACTA Phytophylacica sinica, 20(2): 135-137, 0577-7518

Liu, W.; Liu, Y. \& Chen, P.(1984).The primary identification of soybean cyst nematode in part of county of NorthEast region in China. Journal of Shenyang Agricultural College, 2: 75-78, 1008-9713

Liu, W. \&Liu, Y.(1985).Resistance test of LiaoNing local soybean cultivars to race 3 of soybean cyst nematode. Scientia Agricultura Sinic , 4:25-29, 0578-1752

Liu, W.; Liu, Y.; Duan, Y.; Wu, A.\& Song, Y. (1998). Selection of resistance genes on the populations of race 1 of heterodera glycines in soybeans. Soybean Science, 17(2): 153-156,1000-9841

Liu, X.; Liu, Y.; Xu, G.; Yu, L.; Qu, D. \& Song, S. (1992). Studies on soybean cyst nematode in Jilin Province. Journal of Jilin Agricultural Sciences, 14(1): 5-9, 1003-8701

Liu, Y.; Liu, W.\& Sun, T.(1987).Tests of resistance of local soybean varieties from northeastern China to race 1 and 3 of soybean cyst nematode.Journal of Shenyang Agricultural University, 18(4): 41-44, 1008-9713 
Liu, Y.\& Liu, W.(1989).Identification of races in soybean cyst nematode (second report). Journal of Shenyang Agricultural University, 20(1): 41-44, 1008-9713

Liu, Z.; Lu, W.; Chang, R. \& Qiu,L. (2008). Creation of new soybean SCN4 Resistant Lines. Soybean Science, 27(6): 911-914,1000-9841

Li,Y.; Zhang,C.; Gao,Z.; Marinus,J.; Ma,Z.; Liu,Z.; Nan,H.; Chang,R. \& Qiu,L. (2009). Development of SNP markers and haplotype analysis of the candidate gene for rhg1, which confers resistance to soybean cyst nematode in soybean. Molecular Breeding, 24: 63-76, 1380-3743

Lu, W.; Gai, J. \& Li, W. (2006). Sampling survey and identification of races of soybean cyst nematode (Heterodera glycines Ichinohe) in Huang-Huai valleys. Scientia Agricultura Sinica, 39(2): 306-312, 0578-1752

Lu, P.\& Fang, J. (2003). Express analysis of cDNA induced by infecting roots of soybean cyst nematode race 4 in soybean ZZD2315. Molecular Plant Breeding 1(2 ): 193-200, 1672416X

Ma ,Y.; Wang ,W.; Liu ,X.; Ma ,F.; Wang ,P.; Chang, R.; \& Qiu, L. (2006). Characteristics of soybean genetic diversity and establishment of applied core collection for Chinese soybean cyst nematode resistance. Journal of Intergrative Biology, 48(6): 722-731, 1744-7909

Ma, S.; Zhang, Y.; Xue, Q.; Wu, H.; Liu, H.; Shang, S.; Huo, H.; Wang, F.\& Gao, G. (1991). Evaluation of resistance of soybean germplasm to race 3 of soybean cyst nematode. Soybean Science, 10(3): 165-171, 1000-9841

Ma, S.; Zhang, Y.; Xue, Q.; Yao,Y.; Liu,A.; Huang,C.; Li,Y.; Li,Z.; Wang,F.; Gao,T.; Tian,Z. \& You,Q. (1996). Evaluation of resistance of soybean germplasms of China to race 3 soybean cyst nematode. Soybean Science, 15(2): 97-102, 1000-9841

Matson, A. \& Williams, L. (1965). Evidence of a fourth gene for resistance to the soybean cyst nematode. Crop Science, 5: 477, 0011-183X

Meksem, K.; Jamai, A. \& Ruben, E. (2005) QTLs for resistance to soybean cyst nematode: an Xa21 like gene family that requires possible dimerization for signal transduction. In: Plant and animal genomes XIII conference. Available via DIALOG. http://www.intl-pag.org/13/abstracts/PAG13_W310.html. Accessed 15-19 Jan 2005

Melito, S.; Heuberger, A.; Cook, D.; Diers, B.; MacGuidwin, A.; \& Bent, A. (2010). A nematode demographics assay in transgenic roots reveals no significant impacts of the Rhg1 locus LRR-Kinase on soybean cyst nematode resistance. BMC Plant Biology, 10: 104, 1471-2229

Meng, X.; Liu, XY. \& Fang, XJ. (2003). QTL mapping genes conferring nematode in Soybean ZDD2315 public molecular genetic linkage resistance to race 4 of soybean cyst (Glycine max (L) Merr.) based on map. Molecular Plant Breeding, 1(1): 6-21, 1672-416X

Nan,H.; Li,Y.; Chang,R. \& Qiu,L.(2009). Development and identification of InDel markers based on rhg1 gene for resistanceto soybean cyst nematode (Heterodera glycines Ichinohe). ACTA Agronomica Sinica, 35(7): 1236-1243, 0496-3490

Niblack, T.; Arelli ,P.; Noel, G.; Opperman, C.; Orf, J.; Schmitt, D.; Shannon, J. \& Tylka,G. (2002). A revised classification scheme for genetically diverse populations of Heterodera glycines. Journal of Nematology, 34.,279-288, 0022-300X 
Qiu,L.; Li,Y.; Guan,R.; Liu,Z.; Wang,L. \&Chang,R. (2009). Establishment representative testing and research progress of soybean core collection and mini core collection. ACTA Agronomica Sinica, 35(4): 571-579, 0496-3490,

Qiu, L.; Chang, R.; Wang, W.; Perry, C.; Dechun, W.; Chen, Y. \& Ma, F. (2003). Single nucleotide polymorphism ( SNPs) at both loci of rhg1 and Rhg4 in soybean resistant germplasm. Journal of Plant Genetic Resources, 4 (2) :89-93, 1672-1810

Rao-Arelli, A. (1994) Inheritance of resistance to Heterodera glycines race 3 in soybean accessions. Plant Disease, 78: 898-900, 0191-2917

Riggs, R. \& Schmitt, D. (1988). Complete characterization of the race scheme for Heterodera glycines. Journal of Nematology, 20(3): 392-395, 0022-300X

Ross, J. (1962). Physiological strains of Heterodera glycines. Plant disease reporter, 46: 766-769.

Ruben, E.; Jamai, A.; Afzal, J.; Njiti, VN.; Triwitayakorn, K.; Iqbal, MJ.; Yaegashi, S.; Bashir, R.; Kazi, S.; Arelli, P.; Town, CD.; Ishihara, H.; Meksem, K. \& Lightfoot, DA. (2006) Genomic analysis of the rhg1 locus: candidate genes that underlie soybean resistance to the cyst nematode. Mol Genet Genomics 276:503-516, 1617-4623.

Shang, S. \& Liu, H. (1989) The distribution of soybean cyst nematod races in the Northeast region in China. Soybean Science, 8 (4), 382, 1000-9841

Schmutz, J.; Cannon, S.; Schlueter, J.; Ma, J.; Mitros, T.; Nelson, W.; Hyten, D.; Song, Q.; Thelen, J.; Cheng, J.; Cheng, J.; Xu, D.; Hellsten, U.; May, G.; Yu, Y.; Sakurai, T.; Umezawa, T.; Bhattacharyya, M.; Sandhu, D.; Valliyodan, B.; Lindquist, E.; Peto, M.; Grant, D.; Shu, S.; Goodstein, D.; Barry, K.; Futrell-Griggs, M.; Abernathy, B.; Du, J.; Tian, Z.; Zhu, L.; Gill, N.; Joshi, T.; Libault, M.; Sethuraman, A.; Zhang, X.; Shinozaki, K.; Nguyen, H.; Wing, R.; Cregan, P.; Specht, J.; Grimwood, J.; Rokhsar, D.; Stacey, G.; Shoemaker, R. \& Jackson, S. (2010). Genome sequence of the palaeopolyploid soybean. Nature, 463: 178-183, 0028-0836

Tian, Z.; Gao, G.; Zhou, C.; Du, Z.; Wu, Y.; Wang, M.; Yang, L. \& Li, J. (2007). Study on the variation of soybean cyst nematode. Soybean Science, 26(2): 290-292, 1000-9841

Wang, D.; Lu, W.; Ma, Y.; Liu, N.; Chen, S.; Zheng, J.; Yang, Z.; Liu, R. \& Zhi, H. (2009). Evaluation of resistance of soybean cultivars to soybean mosaic virus and soybean cyst nematode. Soybean Science, 28(6):949-953, 1000-9841

Wang, H.; Yu, B.; Duan, Y. \&Chen , L. (2007). A sensitive molecular marker SSR associated with resistant gene to heterodera Glycines. Soybean Science, 26(2): 204-212, 1000-9841

Wang, J.; Cheng, D.; Wan, Y. \& Fang, X. (2001). Genetic analyzing of resistance to race 4 of soybean cyst nematode in soybean ZDD2226. Chinese Agricultural Science Bulletin,17(6): 12-15, 1000-6850

Wang, L.; Zhao, R.; Wang, L.; Yan, S.; Chen, P. \&Li, Q. (2002). Study on soybean breeding for resistance to cyst nematode. Scientia Agricultura Sinica, 35 (5) : 476-481,0578-1752

Wang, S. (2004). Creation of new soybean SCN3-resistant varieties. Journal of Plant Genetic Resources, 5 (1) :62-64,1672-1810

Wang, S.; Li, W.; Liu, S.; Lu, W.; Liang, H.; Wang, T.; Zhang, H.; Zhao, Z. \& Sun, W. (2004). Genetic analysis of resistance to soybean cyst nematode (SCN) race 1 in soybean germplasm Yingxianxiaoheidou. Journal of Henan Agricultural Sciences, 5: 29-31, 1004-3268

Wang, W.; Qiu, L.; Chang, R.; Ma, F.; Xie, H. \& Lin, F. (2003). Characteristics of alleles at satt309 locus associated with rhg1 gene resistant to scn of Chinese soybean germplasm. Soybean Science, 22 (4 ): 246-250,1000-9841 
Wang ,Z.; Li, Y.; Mu, Z.; Tian, Q. \& Shi, Y.(2005). Evaluation of soybean germplasm for resistance to race 4 of the soybean cyst nematode, Soybean Bulletin, 1: 11-12, 10092765

Wu, HL.; Shang, SG. \& Liu, HQ. (1989). The resistance to SCN of Long84-783 etc soybean new line, Crops,1: 9, 1001-7283

Wu, HL.; Yao, ZC.; Li, XL.; Liu, HQ. \& Shang, SG. (1982) Studies on the screening of resistant sources to cyst nematode of soybean. Scientia Agricultura Sinica, 6:19-24, 0578-1752

Wu, T.; Yang, Q. \& Zhao, S.(1992).Identification method for soybean cyst nematode and analysis of inheritance of resistance of race 3.Journal of Northeast Agricultural College,23(4):322-327, 0253-228X

$\mathrm{Xu}, \mathrm{G}$. (1992). Evaluation of soybean germplasm for resistance to race 3 of the soybean cyst nematode, China Seeds,1: 31-32,1000-6435

Xu, R.; Hao, X.; Wang, C.; Jiang, H.; Li, J. \& Shi, C. (2003). Selection of an elite summer soybean line Lu99-2. Journal of Plant Genetic Resources, 4 (3): 228-231, 1672-1810

Xu, W.; Sheng,H.; Miao, X. \& Yao, W.(2007). Indentification of soybean germplasm resistant to soybean cyst nematode. Soybean Science, 26(3): 377-380, 1000-9841

Yang, L.; Shi, C.; Tian, Z.; Zhou, C.; Li, J.; Wu, Y.\&Du, Z.(2010).Mapping QTL associated with resistance to soybean cyst nematode race 3 in cultivar Kangxian 2.Soybean Science ,29(2):215-217, 1000-9841

Yan, Q.; Chen, P. \& Wang, L. (1995). The verification of race 4 of soybean cyst nematode in suburban Beijing. Soybean Science, 14(4): 355-359, 1000-9841

Yu, B.; Wang, J. \&Ma, S. (2001). Resistance evaluation of major soybean varieties to race 3 of soybean cyst nematode in Heilongiiang province.Journal of Shenyang Agricultural University, 32(3): 181-182, 1008-9713

Yu, B. \& Wang, J. (2004). Evaluation of New Soybean Lines of different regions for resistance to race 3 of soybean cyst nematode. Journal of Laiyang Agricultural College, 21 (2): $115-117,1001-3717$

Yu, B.; Duan, Y.; Wang, J.; Li, J. \& Chen, L. (2009). Selection of virulent phenotypes from an original race 3 population of heterodera glycines by resistant cultivars. Soybean Science, 28(3): 491-494, 1000-9841

Yuan, C. (2007). Development and application of SNP markers of candidate resistance gene Rhg4 and GmHs1pro-1 and discovery of new resistance gene for soybean cyst nematode in soybean. Ph.D Dissertation. Chinese Academy of Agricultural Sciences

Yuan, C.; Li, Y.; Liu , Z.; Guan, R.; Chang, R. \& Qiu, L.(2007). A method of SNP genotyping in soybean. Soybean Science, 26(4): 447-459, 1000-9841

Yuan, C.; Lu, W.; Liu , Z.; Li, Y.; Li, W.; Guan, R.;Chang, R.\& Qiu, L.(2008). SSR analysis of new developed soybean lines resistant to soybean cystnematode (Heterodera Glycines Ichinohe) race 4. ACTA Agronomica Sinica , 34(10): 1858-1864, 0496-3490

Yuan, C.; Zhou,G .;Li, Y.;Wang,K.;Wang,Z.;Li,X.;Chang,R .\&Qiu,L.(2008).Cloning and sequence diversity analysis of GmHs1pro-1in Chinese domesticated and wild soybeans. Molecular Breeding, 22: 593-602, 1380-3743

Zhang, L. (1988). The races of SCN discovered in the north region of Anhui province. Soybean Science, 7(3): 251-254, 1000-9841 
Zhang, L. (1995). Study on identification of soybean germplasm resistant to race 5 of soybean cyst nematode. Journal of Anhui Agricultural Sciences, 23(2): 131-132, 05176611

Zhang, L. \& Dai, O. (1991). Study on identification of soybean germplasm to race 4 of soybean cyst nematode. Journal of Anhui Agricultural Sciences, 3: 265-269, 0517-6611

Zhang, L.\& Dai, O. (1992). Study on identification of soybean germplasm to race 5 of soybean cyst nematode. Soybean Science, 11(1): 79-82, 1000-9841

Zhang, L.; Dai, O.; Liu, J. \& Li, J. (1998). Evaluation of resistance of soybean germplasms of China to race 5 of soybean cyst nematode. Soybean Science, 17(2): 172-175, 1000-9841

Zhang, L.; Li, F. \& Dai, O.(1990).Studies on a new physiological race(race NO.5) of soybean cyst nematode. Journal of Anhui Agricultural Sciences, 4: 322-325, 0517-6611

Zhang, W.; Jiang, H.; Li, C.; Qiu, P.; Qi, Z.; Liu, C.; Jiang, W.; Wang, J.; Hu, G. \& Chen, Q. (2010). Integration of QTLs related to soybean cyst nematode resistance based on meta-analysis. Chinese Journal of Oil Crop Sciences, 32 (1): 104-109, 1007-9084

Zheng, Y.\& Yan, S. (1997). Identification of races of soybean germplasm and evaluation of the resistance of soybean germplasms. Plant Protection, 4: 31-32, 0529-1542 


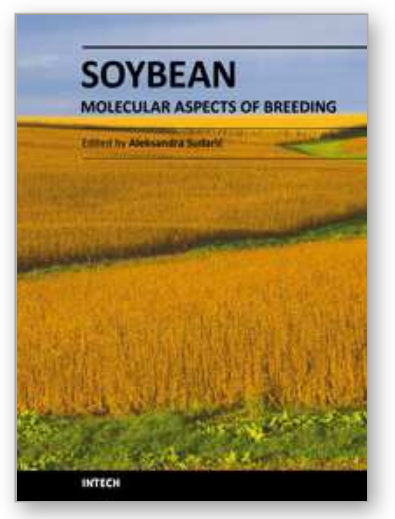

\author{
Soybean - Molecular Aspects of Breeding \\ Edited by Dr. Aleksandra Sudaric
}

ISBN 978-953-307-240-1

Hard cover, 514 pages

Publisher InTech

Published online 11, April, 2011

Published in print edition April, 2011

The book Soybean: Molecular Aspects of Breeding focuses on recent progress in our understanding of the genetics and molecular biology of soybean and provides a broad review of the subject, from genome diversity to transformation and integration of desired genes using current technologies. This book is divided into four parts (Molecular Biology and Biotechnology, Breeding for Abiotic Stress, Breeding for Biotic Stress, Recent Technology) and contains 22 chapters.

\title{
How to reference
}

In order to correctly reference this scholarly work, feel free to copy and paste the following:

Ying-Hui Li, Xiao-Tian Qi, Ruzhen Chang and Li-Juan Qiu (2011). Evaluation and Utilization of Soybean Germplasm for Resistance to Cyst Nematode in China, Soybean - Molecular Aspects of Breeding, Dr. Aleksandra Sudaric (Ed.), ISBN: 978-953-307-240-1, InTech, Available from:

http://www.intechopen.com/books/soybean-molecular-aspects-of-breeding/evaluation-and-utilization-ofsoybean-germplasm-for-resistance-to-cyst-nematode-in-china

\section{INTECH}

open science | open minds

\section{InTech Europe}

University Campus STeP Ri

Slavka Krautzeka 83/A

51000 Rijeka, Croatia

Phone: +385 (51) 770447

Fax: +385 (51) 686166

www.intechopen.com

\section{InTech China}

Unit 405, Office Block, Hotel Equatorial Shanghai

No.65, Yan An Road (West), Shanghai, 200040, China

中国上海市延安西路65号上海国际贵都大饭店办公楼405单元

Phone: +86-21-62489820

Fax: $+86-21-62489821$ 
(C) 2011 The Author(s). Licensee IntechOpen. This chapter is distributed under the terms of the Creative Commons Attribution-NonCommercialShareAlike-3.0 License, which permits use, distribution and reproduction for non-commercial purposes, provided the original is properly cited and derivative works building on this content are distributed under the same license. 